Cuadernos de Filología Clásica. Estudios Latinos

ISSN: 1131-9062

http://dx.doi.org/10.5209/cfcl.73009

\title{
La presencia de Terencio en Quevedo
}

\author{
Elena Gallego Moya ${ }^{1}$; Francisca Moya del Baño²
}

Recibido: 2 de septiembre de 2020 / Aceptado: 26 de noviembre de 2020

Resumen. En estas páginas se estudia la presencia, escasa pero importante, de Terencio en Quevedo. Se muestra que nuestro autor leyó al poeta latino y acudió a sus textos para apoyar sus ideas. La atención que dedicamos a estos textos, pertenecientes a cinco de las seis comedias terencianas, pone a la vista sus intereses, su modo de trabajar y también algunos libros que formaron parte de la biblioteca quevediana; en ella estaba el ejemplar de un Terentius de 1560, que lleva su firma.

Palabras clave: Terencio; Quevedo; Humanismo; libros; comentario de texto.

\section{[en] The presence of Terence in Quevedo}

\begin{abstract}
These pages study the scarce but significant presence of Terence in Quevedo's work. It is shown that Quevedo read the Roman poet and turned to his texts to find support for his own ideas. The attention we have devoted to these texts, belonging to five of the six comedies by Terence, highlights his interests, his way of working and some books that were part of Quevedo's library, such as a copy of Terentius from the year 1560, signed by him.
\end{abstract}

Keywords: Terence; Quevedo; Humanism; books; text commentary.

Sumario: 1. Introducción. 2. Las citas de Terencio en la obra de Quevedo. 3. Dos textos de Terencio en el Rebusco de apuntamientos autógrafos de Quevedo. 4. A modo de conclusión.

Cómo citar: Gallego Moya, E.; Moya del Baño, F., «La presencia de Terencio en Quevedo», Cuad. Filol. Clás. Estud. Lat. 40.2 (2020), 291-306.

\section{Introducción}

Es sabido desde siempre que Quevedo leyó a todos o a casi todos los autores grecolatinos. También es reconocido que la comedia, tanto latina como griega, sirvió de alimento literario a nuestro autor. El nombre de Terencio no podía, pues, faltar en la obra de Quevedo. Es, además, uno de los pocos autores de los que se conserva un

\footnotetext{
$1 \quad$ Universidad de Murcia

Correo electrónico: egallego@um.es

2 Universidad de Murcia

Correo electrónico: fmoya@um.es
} 
ejemplar de sus obras que fue propiedad de Quevedo, uno de la edición de Petrus Antesignanus ${ }^{3}$, publicada en Lyon en 1560:

Terentius, in quem triplex edita est P. Antesignani Rapistagnensis Commentatio: primum exemplar commentariolum est ex omni interpretationum genere (...), secundum exemplar praeter singula contenta in primo, omnium fere quotquot sunt qui in Terentium aliquid ediderunt, commentarios, expositiones, annotationesque complectitur, tertium exemplar ex omnium interpretum commentariis compendiosam expositionem, omneque primi exemplaris argumentum, Gallicam praeterea translationem ad verbum in tres priores comoedias (...) continet: horum omnium ratio in praefatione reddita est. Editio secundi exempl., Lugduni, apud Mathiam Bonhome, sub Clava aurea, $1560^{4}$.

Es, pues, el segundo ejemplar de una edición (editio secundi exemplaris), que, como se dice en ella, consta de tres volúmenes o ejemplares. El de Quevedo lo guarda la Biblioteca histórica de la Universidad de Salamanca; su signatura es USAL $\mathrm{BG} / 33674^{5}$, y, como se ha recordado, lleva su firma. Es muy probable que Quevedo adquiriese y tuviese los otros dos volúmenes; los tres son del mismo año

Tenía en su biblioteca a Terencio y hay textos de Terencio en la obra quevediana, extremo que avala, en principio, lo que nos proponemos mostrar, que lo leyó y lo utilizó. Se trata de citas en latín, salvo un caso en que ofrece Quevedo su versión de un texto. Además de las citas, contamos igualmente con dos textos que aparecen en el Rebusco de Apuntamientos autógrafos ${ }^{7}$. Los comentaremos en estas páginas y procuraremos extraer algunas conclusiones. Comenzamos con las citas.

\section{2- Las citas de Terencio en la obra de Quevedo}

Terencio -hay que reconocer- es un autor cuyos textos son de escasa o, por mejor decir, escasísima presencia en la obra de Quevedo. Solo dos breves citas en latín encontramos en su obra (Moya, 2014, 378s.). Se añade un texto en la versión castellana de don Francisco. Los comentaremos.

\section{2.a. Andria 468}

Adeon'est demens ex peregrina? ${ }^{8}$

\footnotetext{
Petrus Antesignanus (ca. 1524/1525-1561): Pierre Davantès, filólogo protestante francés, experto en griego, latín y hebreo.

4 Nos referiremos a esta edición como "su ejemplar" o "su edición"; lógicamente, de Quevedo.

5 Además de haber sido propiedad de Quevedo, lo fue del obispo de Catania, Ottavio Branciforte. Bajo el nombre, tachado, de Quevedo, se lee su "Ex libris". $C f$. https://bibliotecageneralhistorica.usal.es/?q=persona/branciforteottavio\#expanded [21/08/2020].

6 Pueden verse las ediciones de Terencio publicadas en Francia antes del siglo XVII en Pettegree; Walsby (2012, 1538).

7 Volveremos sobre ello.

8 Traducción de Rubio $(1957,151)$ : “¿Tan loco ha de estar? ¿De una forastera?”.
} 
Se lee en Respuesta al Padre Pineda (Buendía, 1958, 391) ${ }^{9}$. En contestación a una de las críticas que el jesuita e inquisidor le había hecho, Quevedo, de la manera que suele hacerlo, reconoce haber dicho lo que dijo, porque era verdad, pero no lo era lo que el Padre Pineda le censura. Su defensa la sostienen los textos.

Hablaba Quevedo en su Política de Dios, capítulo segundo de su Primera Parte, del Rey Salomón (Díaz Martínez; Cacho Casal, 2012, 223), del que decía, entre otras cosas, que "supo pedir y recibió sabiduría y riquezas", o que "fue más conocido por 'Sabio' que por su nombre". Seguía diciendo que "él es proverbio del mejor don de Dios y que sus palabras son el firmamento de la prudencia por donde se gobierna toda la navegación de nuestras pasiones". Sin embargo, también añadía algo que Pineda no vio con buenos ojos y sí digno de ser censurado. Se trata de esta frase: "Y siendo una vez rey, trescientas fue reino de otras tantas rameras ${ }^{10}$.

El texto de la censura de Pineda decía así:

Folio 10, página 1, llama a las trescientas concubinas de Salomón 'otras tantas rameras'. Las concubinas que llama la Escritura no eran rameras, sino legítimas mujeres, aunque menos principales que las que llaman uxores.

Quevedo en su "Respuesta" reproduce el texto de Pineda, reconociendo que, en efecto, eso que critica es lo que está impreso, pero preguntándole, a su vez, con no poca ironía, la razón de haberle atribuido el haber dicho que las concubinas eran rameras; él -añade- no ha mencionado a las concubinas. Ahora bien, también dice que no cree que Pineda ignore que en la vida de Salomón hay muchas mujeres que él podría llamar rameras, como se desprende del libro tercero de los Reyes, cap. XI $<1-2>^{11}$ :

Rex autem Salomon adamauit mulieres alienigenas multas, filiam quoque Pharaonis, et Moabitidas, et Ammonitidas, Idumaeas, et Sidonias, et Hethaeas: de gentibus, super quibus dixit Dominus filiis Israel: Non ingrediemini ad eas, neque de illis ingredientur ad uestras ${ }^{12}$,

y añade que con el número de trescientas indicaba que eran muchas ${ }^{13}$, y que sí eran rameras, pues eran mujeres que Salomón trató contra lo que Dios manda ${ }^{14}$.

Quevedo omite el texto que sigue en Reyes, pese a que es precisamente aquí donde aparecerán las "trescientas rameras" que criticaba Pineda ${ }^{15}$, concretamente

$9 \quad$ Sobre esta obra y sus versiones, recientemente, Alonso Veloso (2019).

10 En nota ( $n^{\circ}$ 161), Díaz Martínez; Cacho Casal dicen: 'aun existiendo realmente un ejemplo de buen rey (tal fue el caso de Salomón), trescientos casos hubo de reinos corruptos'.

11 En Buendía se lee II en vez de XI. El texto es de la Vulgata, 3Reyes XI 1-2. Hemos corregido alguna errata en el texto latino.

12 Tr.: "El rey Salomón amó a muchas mujeres extranjeras: moabitas, amonitas, edomitas, sidonias e hititas, también a la hija del Faraón, mujeres de pueblos acerca de los cuales dijo el Señor a los hijos de Israel: "No las poseáis a ellas, ni posean los de ellos a las vuestras". (Las traducciones, si no se indica autor, son nuestras).

13 Cf. infra. El texto de 3Reyes hablaba de "setecientas esposas y reinas", número que está, lógicamente, por 'muchas'. No es casualidad que se diga 300 y 700; su suma es otro número indicador de una multitud.

14 Dios, dice el libro de la Biblia mencionado, habló a los israelitas; cf. non ingrediemini ad eas (...).

15 Antes de indicar el número de mujeres, se refería a lo inconveniente de estas relaciones amorosas del rey Salomón: certissime enim auertent corda uestra ut sequamini deos earum. His itaque copulatus est Salomon ardentissimo amore. ("Pues con toda certeza volverán vuestros corazones al seguimiento de los dioses de estas. 
en el versículo 3: Fueruntque ei uxores quasi reginae septingentae, et concubinae trecentae: et auerterunt mulieres cor eius ${ }^{16}$.

Quevedo - hay que reconocer- no había dicho "concubinas", aunque en el texto de la Vulgata Pineda había leído concubinae. Pero dejemos el texto de Reyes, que, ciertamente, fue la fuente de Quevedo y que hablaba de rameras para las que el rey Salomón fue "su reino".

Aporta, a continuación, en su "defensa" un texto de Isaías y otro de san Juan Crisóstomo; con ellos apoya que las mujeres de Salomón de las que habla la Biblia pueden ser llamadas rameras o meretrices, peregrinas o extranjeras, y luego insiste en que los hebreos llaman a las rameras 'peregrinas' y 'extranjeras' ${ }^{17}$; y también los latinos; y es entonces cuando, en esa acumulación de textos, aduce -llegamos ya a Terencio- el texto de Andria.

Simón, padre del joven Pánfilo, que ama a una cortesana, se escandalizaba 'al enterarse' de que su hijo había sido capaz de reconocer como hijo suyo al que había dado a luz una meretrix, refiriéndose a ella como peregrina, término que es casi sinónimo de alienigena, como veíamos en Reyes, porque ella era una extranjera ${ }^{18}$; a las extranjeras se las tenía en Roma por deshonestas y meretrices. Por eso Simón piensa que Pánfilo está loco al haber tenido un hijo con esta muchacha y al reconocerlo como hijo suyo; de ahí que exclame: “¿Hasta tal punto ha enloquecido? ¿De una extranjera?”.

Quevedo, que ofrecerá más avales para justificar la utilización del término 'ramera', que no es otra cosa que meretrix, como en Terencio peregrina, acudió al comediógrafo latino, del que podía recordar el verso, pero no su ubicación en la obra $^{19}$ : pudo recordarlo o tenerlo copiado en sus papeles. Sea como fuere, añadió a los testimonios de los textos sagrados la auctoritas de un autor clásico de enorme prestigio siempre, también en ese momento de la literatura áurea.

En fin, Quevedo había dejado claro que Salomón, aunque le pesara al Padre Pineda, había gozado de muchas rameras. Don Francisco, que había elogiado las grandes virtudes del rey sabio, tenía, sin embargo, que hablar también de los vicios, en su caso, de su lujuria, como lo avala lo que sigue en Política de Dios ${ }^{20}$.

\section{2.b. Heautontimoroumenos 796}

Ius summum saepe summa malitia est $t^{21}$

La segunda cita la leemos en Política de Dios, capítulo tercero de la Primera Parte (Díaz Martínez; Cacho Casal, 2012, 230). También ofrece, como importante aval, las

Y así con estas copuló con apasionado amor Salomón”.)

16 Tr.: "Tuvo setecientas esposas casi reinas y trescientas concubinas. Y las mujeres desviaron su corazón”, es decir, 'alejaron su corazón de Dios'.

17 En latín alienigena y peregrina eran y son casi lo mismo que meretrix.

18 Lógicamente antes de que se descubriese el enredo.

19 Pertenece al Act. III, sc. I. En su edición se lee en p. 106, en el comentario al lema Adeo est. ex p.: "Mulieres enim peregrinae, inhonestae et meretrices habebantur".

20 Dirá que todos los emperadores griegos y romanos han sido esclavos de sus vicios, y añade: "Donde la lujuria no ha hallado puerta (...), ha entrado a ser monarca o el descuido o la venganza o la pasión (...). Solo Cristo Rey pudo decir: Quis ex uobis arguet me de peccato? < ¿Quién de vosotros me acusará de un pecado?”> (Ioan. $8<46>$ )". Cf. Díaz Martínez; Cacho Casal (2012, 223).

21 Trad. Rubio $(1961,90)$ : "Suprema justicia es con frecuencia suprema maldad". 
palabras de Terencio, uno de los autores ‘idólatras', como suele Quevedo -y se solíallamar a los clásicos grecolatinos frente a los bíblicos o patrísticos.

Hablaba Quevedo de la justicia ${ }^{22}$, que "se muestra en la igualdad de los premios y los castigos, y en la distribución, que algunas veces se llama igualdad", y se detiene en ella diciendo que:

esta virtud quiere ser tratada y poseída con tal cuidado y moderación como aconseja el Espíritu Santo cuando dice: Noli nimium esse iustus ${ }^{23}$, pecado en que incurren los que tienen autoridad en la república y son vengativos (...). Estos son alevosos, no jueces; traidores y sacrílegos, no Príncipes.

\section{Y continúa:}

San Agustín lo entendió así, cuando dijo: Iustitia nimia incurrit peccatum: temperata uero iustitia facit perfectionem ${ }^{24}$. No se desdeñó esta verdad de las plumas de los idólatras, pues Terencio, en la comedia que llamó Heautontimorumenos, dijo: Ius summum summa saepe ${ }^{25}$ malitia est ${ }^{26}$.

También esta cita de Terencio le pudo venir a la mente cuando escribió lo que decía el Eclesiastés, o san Agustín en sus Quaestiones in uetus nouumque Testamentum $^{27}$, pues a esta obra pertenece el texto citado, aunque lo que se lee en Quevedo no es exactamente igual a lo que aparece en las ediciones que pudo leer $^{28}$. Hay entre ellas una leve diferencia en el orden de palabras: Nimia iustitia frente a Iustitia nimia, y perfectos frente a perfectionem, que se lee en Quevedo.

Tampoco, como ocurría en la anterior cita, se indica aquí en qué lugar de la comedia sitúa este verso Terencio. Pudo haberlo leído Quevedo en una edición de sus Comedias $^{29}$ o ser una cita indirecta, pues era un texto muy conocido y citado en Sentencias, Refranes, obras de materia jurídica, etc. ${ }^{30}$.

22 Tema fundamental y frecuente entre los humanistas, que acudían a los textos grecolatinos en sus obras y comentarios a las leyes. Quevedo, como es sabido, estaba muy interesado en estas cuestiones fundamentales del derecho, leyes, justicia, etc., y leía, sin duda, todo lo que trataba el tema; posiblemente leyó las Annotationes a las Pandectas de Guilielmus Budaeus, que abre y continúa el capítulo "De prima lege. De iustitia et iure" con textos de Terencio. En la edición de 1542, leemos el mencionado texto de Heautontimorumenos en página 3. Y, por otra parte, puede valer de ejemplo de su interés por el derecho el hecho de que era de su propiedad un manuscrito en pergamino del Fuero Juzgo de Toledo; así lo dice en su España defendida; cf. Moya; Miralles $(2018,115)$, o la presencia en el Rebusco de varios 'apuntamientos' sobre estas cuestiones.

23 "No seas demasiado justo". Son palabras del Eclesiastés 7.17. Así se leen en muchas obras del Humanismo, pero en la Vulgata se lee: Noli esse iustus multum. No las tomó, pues, Quevedo de la Vulgata, ni de obras que citaran por ella.

24 "Una demasiada justicia incurre en el pecado; pero una justicia moderada logra la perfección".

25 Quevedo escribe summa saepe, en lugar de la lectura de los códices y ediciones terencianos (saepe summa); sin duda, se trata de un despiste normal en él, y no solo en él.

26 "El sumo derecho a menudo es la suma maldad".

27 Lo hace, concretamente, en la "quaestio XV ex Veteri Testamento", comentando el texto de Eclesiastés 7.

28 Pudo ser el texto de la edición de 1561. Esta obra consta de dos volúmenes. cf. Augustinus (1561, II 18). Aquí, en el segundo, se encuentra el texto que cita Quevedo.

29 Está en la p. 446 de su ejemplar. Pertenece al Act. IV, sc. 1.

30 Por ejemplo, lo vemos en Nebrija, al final de la Epístola nuncupatoria que precede a su edición de los Libri minores; la dirige al Reverendo Padre y clementísimo señor don Juan de Fonseca, arzobispo de Rossano y obispo 
Sin embargo, creemos, con casi toda seguridad, que la cita de Terencio, como las de san Agustín y Eclesiastés, las tomó Quevedo de un libro que también le gustaría leer: Symbolorum Imperatorium Classis secunda, que dio a la luz Reusner ${ }^{31}$, en concreto del symbolum XXVI. Era de Fl. Anicius Iustinianus, es decir, el emperador Justiniano I, y reza así: Summum ius summa iniuria ${ }^{32}$. Ocupa las páginas 111-115. En la página 114 están juntos, y también sin localización de citas, los textos que menciona Quevedo; aparecen, además, de modo idéntico a como él los cita: Noli nimium esse iustus del Eclesiastés y Iustitia nimia incurrit peccatum (...) facit perfectionem, de san Agustín.

Es, pues, evidente que las citas de Quevedo coinciden con las de esta obra. Su idea de lo que debe ser la justicia ${ }^{33}$ se compadecía muy bien con lo que leía en este symbolum. Y, aunque el texto de Terencio le fuera familiar y lo hubiese podido añadir, lo cierto es que estaba citado también en la página 112. Se leía igual que en todas las ediciones y menciones. Parece lógico deducir que Quevedo fue el que cambió el orden de palabras y puso juntos summum y summa. Pudo ser -insistimos- un despiste o quiso darle mayor fuerza al dictum con la unión de los adjetivos. También en este symbolum se lee, como suele escribirse, ius summum saepe summa malitia est.

Con este texto de Terencio hemos podido descubrir un nuevo libro, curioso e interesante, de la biblioteca de Quevedo, la citada obra de Nicolas Reusner.

\section{2.c. Terencio en la Vida de san Pablo ${ }^{34}$}

"Hacen los tribunales frecuentes agravios cuando de lástima dan al pobre lo ajeno, y de envidia quitan al rico lo propio" < Terencio Formión, 275-277>.

En esta obra de Quevedo, como puede observarse, el texto de Terencio no está en latín, sino en traducción de nuestro autor. La cita terenciana va precedida de un juicio de valor y una información: "Con hermosas palabras dijo esto Terencio". Alababa, pues, primero, las palabras de Terencio e informaba después de que con ellas el comediógrafo decía lo mismo que antes había dicho él. Intentaremos situar estas palabras en el contexto en que se encuentran en la obra de Quevedo.

Habla Quevedo de la vida de san Pablo y sigue de cerca los Hechos de los apóstoles. Pablo, acusado por los judíos, es enviado preso a Cesarea; allí permanece en prisión bajo el gobernador Porcio Festo, al que los judíos siguen presentando sus acusaciones (las habían presentado antes a Antonio Félix, que lo precedió como go-

de Burgos. Al hablar de las leyes y el derecho, ofrece, entre otros muchos, este texto. Puede verse en la edición de 1529 (sin paginación) y en Nebrija $(2009,104)$.

31 Nicolaus Reusner, von Reusner o Reusnerus (1545-1602), jurista alemán de gran erudición en diversos saberes y autor de una amplia y variada obra, incluida la poesía.

32 Se lee en Cic. off. 1.10.[3]: Existunt etiam saepe iniuriae calumnia quadam et nimis callida sed malitiosa iuris interpretatione. Ex quo illud "summum ius summa iniuria" factum est iam tritum sermone prouerbium. ("Existen, además, a menudo, injusticias por alguna denuncia falsa y por una interpretación del derecho en exceso hábil pero capciosa. Por ello aquel 'sumo derecho, suma injusticia' se ha convertido ya en un proverbio frecuente en las conversaciones").

33 Cf. Ruiz de la Cuesta (1984, 251-253). Él habla de "La idea de la equidad", en el apartado 1.3 del cap. IX, que lleva por título "Teoría de la justicia en Quevedo", poniendo de relieve el acierto de Quevedo, como reconocen expertos en la materia, a los que cita.

34 Cf. Fernández-Guerra $(1859,43)$. 
bernador). Festo propone a Pablo enviarlo a Jerusalén, pero este se niega, defendiendo que a los judíos no les había hecho mal alguno y que, como ciudadano romano que era, apelaba al César, en este momento Nerón. Estando en esta situación, el rey Agripa llegó a Cesarea y, tras escuchar lo que Festo le decía de Pablo, quiso escucharlo. Pablo le dirige sus palabras -su "oración"- narrando su vida y conversión, y defendiendo su inocencia. El ha predicado -dice- por obediencia a la visión del cielo que tuvo en el camino de Damasco, ha predicado a Cristo muerto y resucitado, y desea que todos se conviertan, como él se convirtió. Agripa, tras escucharlo, considera que no es digno de muerte ni de cárcel, aunque su apelación al César obliga a conducirlo a Roma.

La oratio de Pablo es, a nuestro juicio, una excelente pieza oratoria, que tiene detrás el capítulo 26 de los Hechos, aunque no es una versión completamente fiel; pero lo que nos interesa ahora es escuchar a Quevedo y a Terencio en el pasaje en el que Quevedo, al hablar de Pablo, tiene la vista puesta en el presente. Pablo fue acusado, como tantos otros lo son en la época de Quevedo, como él mismo lo ha sido, y por eso va a ofrecer el panorama de las reacciones ante esta realidad. Para ello, para hablar de acusaciones, calumnias y jueces injustos, cuenta con Terencio. Dice así:

Danos este suceso de san Pablo toda la enseñanza de la acusación apasionada y de la defensa religiosa y cortés. ¡Con cuán precipitada insolencia se precipitan los calumniadores en presencia de los ministros particulares, pues los hemos visto acompañar los oprobios con la violencia de las manos, y a los jueces no solo aplaudir el furor sino mandarle! En esta audiencia, en que presidía el rey Agripa, los judíos no se atrevieron a perderle el respeto, y por fuerza tuvieron vergüenza. En la presencia de las majestades se desalienta la malicia y se anima la inocencia. Los príncipes soberanos, que desde su lugar superior miran a todos, están en cumbre donde no alcanza la envidia ni el miedo, que son interesados asesores. Con hermosas palabras dijo esto Terencio: "Hacen los tribunales frecuentes agravios cuando de lástima dan al pobre lo ajeno, y de envidia quitan al rico lo propio". Festo como ministro bien intencionado, solicitó que el rey oyese a Pablo por sí; diligencia que descaminan con desvelo delincuente los jueces que juzgan por lo que temen o por lo que codician.

Quevedo, mirando al presente, está pensando, sin duda, en quienes lo calumniaron, en los que no lo defendieron ante el rey y en los que fueron más bien jueces parciales, cuando no calumniadores. En contraste, destaca, no muy fielmente, la buena actuación del gobernador Festo. Pero vayamos ya a Terencio.

El comediógrafo viene a la mente de Quevedo para avalarlo con sus sabias y hermosas palabras. Es una autoridad. El texto se compadecía muy bien con lo que él pensaba, y don Francisco hizo "su" versión, que, sin ser idéntica al texto, pues elige el tono aseverativo frente al interrogativo y habla de tribunales en vez de jueces, mantiene el espíritu y casi todos sus términos. Los versos que traslada Quevedo son:

\author{
nostrane ea culpa est an iudicum, \\ quia saepe propter inuidiam adimunt diuiti \\ aut propter misericordiam addunt pauperi? (TER. Phorm. 275-277)
}

35 En la edición de 1560, en p. 776 se lee quia en vez de qui, que es la lectio unánime. Mantenemos quia y modificamos la traducción de Rubio en este caso: él, lógicamente, traduce "que”. $C f$. Rubio $(1961,150)$ : “¿es 
Estas palabras, que van precedidas de una oración condicional ${ }^{36}$, pertenecen a Fedria; este es primo de Antifón, que, en ausencia de sus respectivos padres, se ha casado con Fania, una joven huérfana y pobre. Para poder celebrar esa boda contaron con un cómplice, Formión. Este se presentó ante los jueces para "obligar" a Antifón a casarse con Fania, basándose en que era el pariente más cercano de la muchacha. Y eso es lo que dice Fedria a su tío cuando este le pide explicaciones. Muy seriamente le ha dicho Fedria, con anterioridad, que vería muy bien que, si su Antifón hubiese cometido delitos contra la hacienda $u$ honra de su padre, lo castigase. Pero esto que ha hecho -casarse con Fania- es distinto. Él no tiene la culpa. Una vez llevado ante los jueces por Formión, estos actuaron mal. Estos jueces, o este tribunal, son los que hicieron agravio a Antifón cuando tuvieron lástima de la pobreza de Fania y obligaron al joven a casarse con ella ${ }^{37}$.

Quevedo con Terencio sí que critica de verdad a jueces y tribunales parciales, cuyas decisiones son dirigidas por la lástima o la envidia. Contra él actuarían más bien por envidia. Terencio "lo dice".

\section{Dos textos de Terencio en el Rebusco de apuntamientos autógrafos de Quevedo}

Hasta aquí hemos visto las citas de Terencio en las obras de Quevedo. Sin embargo, y pese a su escasa presencia, se puede afirmar, sin duda alguna, que Quevedo conocía bien al poeta latino; que su ejemplar no había sido solo para lucir en su biblioteca. Sabemos que lo leyó, porque, como veremos, nos ofrece un testimonio evidente de que lo está consultando. Encontramos dos veces más el nombre de Terencio en la pluma de Quevedo.

Como ya hemos recordado en otro lugar (Moya; Gallego, 2020), Fernández-Guerra publicó en 1859 un conjunto de "apuntamientos" autógrafos de Quevedo, que habían sido reunidos por el conde de Saceda y copiados por don Antonio Sánchez, y que llegaron al poder del Director de la Biblioteca Nacional, don Agustín Durán, el cual se los confió para su publicación a él mismo, es decir, a Fernández-Guerra (Fernández-Guerra, 1859, 501). Pasado casi un siglo, también Astrana Marín publicó, con el título de Apuntes particulares y observaciones raras a todo género de autores de don Francisco de Quevedo ${ }^{38}$, un buen número de apuntes, entre los que se encuentran bastantes de los apuntamientos publicados por Fernández-Guerra. En ambos editores se trata de una miscelánea variopinta y muy interesante, en la que predominan los textos sagrados y clásicos, los cuales, a veces, son comentados o dis-

nuestra culpa o es culpa de los jueces, porque con frecuencia por envidia quitan al rico, o por compasión dan al pobre?".

36 Cf. vv. 273ss. y Rubio ib.: sed si quis forte malitia fretus sua/ insidias nostrae fecit adulescentiae/ ac uicit... ("Pero si tal vez alguien, confiado en la propia picardía, ha tendido lazos a nuestros pocos años y se ha salido con la suya...").

37 No hace falta recordar que Antifón quería casarse con Fania, y que el engaño fue que Formión lo llevase ante los jueces para que se casase 'a la fuerza' con Fania.

38 Se leen en Astrana Marín (1945, 1563-1583). En 1940 en su libro Ideario de Don Francisco de Quevedo y Villegas, había publicado dentro del apartado "El humanista polígrafo", algunas, cuatro en concreto, "Observaciones raras a todo género de autores", añadiendo que Tomás Tamayo de Vargas las alababa mucho. Ocupan las páginas 171-173 y son las siguientes: XL, LXI, LXII y LXIII de su edición de 1945, que corresponden a las XIV, XXXVI, XXXVII y XXXVIII de Fernández-Guerra. 
cutidos. Algunos de ellos los vemos citados en las obras de Quevedo. Eran, sin duda, un material para uso propio de don Francisco, pues es bien sabido que acostumbraba a poner en los márgenes de los libros notas de diversa naturaleza y, también, a trasladar a cuadernos cualquier cosa que leía y le parecía interesante ${ }^{39}$. Comentamos ya los apuntamientos terencianos del Rebusco ${ }^{40}$.

\section{3.a. Apuntamiento $X X X^{41}$}

Ioannes, IX: "Scimus autem quia peccatores Deus non audit". Proposición del ciego nato, según el común sentir de los judíos. De aquí los donatistas conantur probare irrita esse sacramenta per peccatores administrata.

Menos errado anduvo Terencio que los judíos y herejes, Adelfos, acto Iv, escena $\mathrm{v}, 703^{42}$ :
Aeschinvs. Abi, pater,
tu potius deos comprecare: nam tibi eos certo scio, quo uir melior multo es, quam ego, obtemperaturos magis ${ }^{43}$.

"Porque eres mejor, te oirán mejor". No niega que a él no lo oyeran, sino que se mostrarán más fáciles a su padre, por ser mejor.

San Agustín con el ejemplo del publicano prueba que oye Dios a los pecadores. Y así, la margen a Terencio en este lugar, en el comentado por Ante-Signano, es sospechosa, y es esta: "Nam peccatores Deus non exaudit".

(Copiado del apuntamiento original de Quevedo que es una hoja suelta en $8^{\circ}$ )

Se trata, ciertamente, de una interesante "nota" en la que se observa, entre otras cosas, que Quevedo conoce a Terencio y que con él, pues es una autoridad, puede incorporarse activamente a un 'diálogo' entre san Agustín y el evangelista Juan, diálogo al que también incorpora, de alguna manera, a Petrus Antesignanus, comentarista de Terencio.

El "apuntamiento" va precedido de una introducción o resumen, que reza así: "Una autoridad de Terencio in Adelph. Act. 4. Scen. 5 para probar contra los Donatistas que: Sacramenta per peccatores administrata possunt ${ }^{44 "}$.

Recoge Quevedo un texto del evangelista Juan (IX 31), en el que se afirma que Dios no escucha a los pecadores (Scimus autem quia peccatores Deus non audit). Esta afirmación está en boca del ciego de nacimiento, al que Jesús ha curado su ceguera (se indica en "proposición de ciego nato"); este respondía, por segunda vez, a

39 Tarsia decía que "andando por las calles en su coche, acostumbraba a llevar consigo papel, y tinta, para apuntar lo que podía ofrecerle su continuada aplicación”, se sobreentiende: a los libros y a la lectura. Cf. Tarsia (1997, 33).

40 Ofrecemos el texto y puntuación del manuscrito M-530 de la Biblioteca Menéndez Pelayo. Nos referimos a él con 'M' o 'manuscrito'.

41 En el manuscrito lleva el número 129, el antiguo. Mantenemos el de Fernández-Guerra (1859, 505). En Astrana Marín $(1945,1577)$ es el apunte XLVI.

42 En el manuscrito se lee 708.

43 Cf. Rubio $(1966,161)$. "Padre, vete más bien tú a invocar a los dioses; pues seguro estoy que a ti, por ser mucho mejor que yo, te harán más caso".

44 En el texto falta el infinitivo. Quevedo reutiliza las palabras que lee en la obra de la que parte. 
las preguntas de los judíos, como seguimos leyendo, y lo que dice es "el común sentir de los judíos". De ahí se deriva que los donatistas intentan dar por bueno que los sacramentos administrados por pecadores no tienen valor ("De aquí los donatistas conantur probare irrita esse sacramenta per peccatores administrata").

A Quevedo no le parece correcto lo que piensan los judíos y los donatistas (los llama herejes, pues de una herejía se trataba), y un texto de Terencio le viene a la mente. Lo que dice Terencio es, a su juicio, más correcto que lo que decían judíos y donatistas. Aporta el texto de Adelfos, y de él traduce el último verso ("Porque eres mejor, te oirán mejor") y explica su significado.

Sigue el apuntamiento aportando la autoridad de san Agustín, que con el ejemplo del publicano ${ }^{45}$ prueba que Dios sí escucha a los pecadores. Y de nuevo vuelve a Terencio para juzgar "sospechoso" lo que él mismo ha leído en la nota marginal al citado texto de Terencio, en la edición de Antesignanus, nota que, lógicamente, Quevedo ha visto en su ejemplar.

Este apuntamiento nos hace preguntarnos: ¿Lo que ha recogido y escrito en su hoja, en octavo, sería para utilizarlo en alguna obra? Es lo más probable. O, sencillamente, ¿leyó algo que captó su interés? También es posible. Lo que es evidente es que lo que copió, "a su manera", al comienzo de su apuntamiento lo encontró en un libro; lo leyó en latín, pero, al pasarlo a su papel, mezcló el latín y castellano (cf. "de aquí los donatistas conantur probare, irrita,...").

Comenzamos por el final. Ciertamente, en la página 578 de la citada edición de Terencio de 1560 se lee: Nam peccatores Deus non exaudit; eso es exactamente lo que copia Quevedo y lo que no le gusta. Es, en realidad, una nota de Bartholomaeus Latomus $^{46}$ (se indica con una L.), no de Antesignanus, como decía don Francisco, aunque también Antesignanus insistirá en su propio comentario, situado detrás del texto, en que los gentiles pensaban así, que los dioses no escuchaban a los pecadores y que, por el contrario, asentían a las personas buenas. Quevedo nos confirma que tenía en su poder y leía la edición de Antesignanus.

Volviendo al principio, sabíamos que la información de este apuntamiento partía de una fuente, y queríamos descubrirla; la descubrimos. Podemos afirmar con casi total seguridad que el texto que copia Quevedo procede del humanista extremeño Juan de Maldonado ${ }^{47}$. Podría haber sido otra su fuente; podría proceder, por ejemplo, del Manuale in Sanctum Iesu Christi Domini nostri Euangelium, de Ioannis Bence. En las páginas 883-884 ("Manuale secundum Ioan. cap. IX") se lee, aparte del principio (Scimus autem quia peccatores Deus non audit), cómo lo interpretaban los donatistas (abutebantur hoc loco donatistae, putantes irrita esse sacramenta per peccatores administrata ${ }^{48}$, etc.). Sin embargo, no es así.

En efecto, "proposición de ciego nato", que leemos en Quevedo, partía, sin duda, de los Commentarii in quatuor euangelistas de Juan de Maldonado; en la edición de 1615, columna 1610, el texto que copia y comenta Quevedo está situado bajo el epígrafe "Comment. in Ioan., cap. IX de coeco nato a Chr. illum<inato>"49, el cual

\footnotetext{
45 Cf. infra.

46 Bartholomaeus Latomus (1485-1570) enseñó griego y latín en Friburgo (Alemania) y elocuencia en París. Luego retórica en varios lugares.

47 Ioannes Maldonatus (1533-1583), jesuita y teólogo. Nos referimos a él con 'Maldonado'.

48 "Abusaban de este lugar los donatistas, que pensaban que eran vanos los sacramentos administrados por pecadores".

49 En la edición de 1602, que se recoge en el Catálogo de la Biblioteca del Monasterio de S. Martín (Mss. BNE
} 
se mantiene en todo el comentario del capítulo noveno, que ocupa las columnas 1597-1616.

Maldonado dedica, ciertamente, un amplio y erudito comentario al mencionado capítulo, como lo hace al versículo 31 que interesó a Quevedo. Maldonado, en nota 43 de este capítulo, admitía que lo que dice el ciego a los fariseos que lo interrogan coincide con la opinión común, y por eso no utiliza la primera persona de singular, sino la del plural, indicando con ello que es algo sabido ${ }^{50}$. Quevedo lo resume en "según común sentir de los judíos", omitiendo otros comentarios de Maldonado sobre esta expresión, que acompaña, como suele, de citas bíblicas. Pasa Quevedo a la nota 45 en la que Maldonado pone de relieve que los donatistas se servían de este lugar del Evangelio para probar que los sacramentos administrados por pecadores no eran válidos, herejía que san Agustín combatiós1 ${ }^{5}$ Quevedo adapta las primeras palabras: De aquí los donatistas conantur probare etc.

Quevedo nada dice ahora de san Agustín y acude directamente a Terencio. Es evidente que no comparte la opinión de los judíos y menos aún lo que defienden los herejes. Está seguro de que Dios escucha a los pecadores y Terencio lo avala, como hemos visto. También pensaba lo mismo san Agustín, como Maldonado dejaba claro en la anterior nota, la 44. A Quevedo, sin embargo, le interesaba más la aportación de Terencio, o, de otra manera, destacar la autoridad del poeta latino (el resumen que precede al apuntamiento lo deja claro). Sin embargo, no va a omitir que san Agustín (también Beda y muchos otros) había acudido al "ejemplo del publicano" para probar que Dios escucha a los pecadores. Maldonado insistía en que muchos disputaban sobre la verdad de una sentencia que dice que Dios no escucha a los pecadores, y añadía que san Agustín, entre ellos, ponía el ejemplo del publicano que, con los ojos clavados en tierra y dándose golpes de pecho, pedía a Dios que fuera benévolo con él, que era un pecador; si Dios no escuchara a los pecadores, el publicano no hubiera dicho Deus propitius esto mihi peccatori ("Dios mío, sé benévolo conmigo, un pecador"), como se lee en Lucas 18, $13^{52}$. Quevedo se ha limitado a mencionar este ejemplo y nada más ha puesto en su apuntamiento. También omite, pues no le interesa, lo que sigue explicando Maldonado, a saber, que san Agustín y otros pensaban que el ciego hablaba como un catecúmeno o neófito que carecía de la necesaria formación cristiana. A nuestro autor le interesa volver a su "libro" de Terencio, juzgando "sospechosa" la nota que leía en el margen del texto de Adelfos.

Este apuntamiento quevediano trata de un tema serio, importante, sin duda, para Quevedo, en el que parte del comentario de Maldonado, al que puede añadir un texto que, diríamos, le aporta tranquilidad, y que valoraría más por ser de un autor pagano. Este apuntamiento ha puesto, pues, ante nuestros ojos un nuevo libro que leyó

1908) y que podría haber sido de Quevedo, no aparece esta información. El texto que copia Quevedo se lee en col. 1647.

50 Así leemos en Maldonado $(1615,1610)$ : Argumentatur autem ex communibus principiis, et recepta apud omnes homines opinione, ut Cyrillus, et Leontius obseruant, ideo non dixisse, scio, sed scimus, id est, uulgo scitum, atque receptum, ut nemo prorsus dubitet.

51 Dice así Maldonado $(1615,1611):$ Abutebantur hoc hoco Donatistae, ut probarent, irrita esse sacramenta per peccatores administrata, ut ex iis locis Augustini adversus Donatistas, quos modo notauimus, perspicuum est. En la nota anterior hablaba Maldonado de san Agustín.

52 Dice la nota 44 de Maldonado (1615, 1610-1611): Disputant tamen multi, quomodo ea sententia in uniuersum uera sit, Deum peccatores non exaudire. In quibus Augustinus hoc loco, et alibi, et Beda, Si enim Deus peccatores non audiret, frustra ille publicanus, inquit Augustinus, oculos in terram demittens, et pectus suum percutiens diceret, Deus propitius esto mihi peccatori. 
Quevedo, los Commentarii in quatuor euangelistas del teólogo español; conantur probare, que procede, con mucha probabilidad, de ut probarent, es otro aval. En el citado Manuale no aparecía el verbo probare. Bence, su autor, ofrecía putantes ${ }^{53}$. Desde luego, era lógico que Quevedo conociera y utilizara esta obra. Podemos afirmar que la utilizó. En cuanto a Terencio, el propio Quevedo nos dice que lo tiene y que lo ha leído.

\section{3.b. Apuntamiento XXIV ${ }^{54}$}

Terentius: Eunuchi, act. III, scena V, v. $52[601]^{55}$.

Ego limis aspecto ${ }^{56}$

Deest "oculis". Nam limis est transuersus: unde limen dicitur quoque, quod ingredientibus, exeuntibusque transuersum est. Cum autem dissimulant homines se uidere quod uident, et non recta facie, sed transuersa intuentur: limes dicuntur aspicere. Cum uero Limi dicantur obliqui generaliter: hoc tamen propie de oculis dicitur $^{57}$.

(Copia del original que es un apuntamiento en una hoja de $16^{\circ}$ ).

Quevedo se limita a copiar una frase y a añadir un comentario a la misma. Quien copió este apuntamiento de Quevedo informa de que procede de una hoja de tamaño mediano, la mitad de la octava parte del folio, es decir, de un papel del tamaño de una ficha. En él escribiría frase y comentario. Es claro que la expresión no le pasó desapercibida. Quizá tampoco el contexto en el que se encuentra.

En la comedia de Terencio, Quérea, el falso eunuco, está informando a Antifón de cómo cuidaba (dicho con ironía) a la muchacha que se le había confiado a su protección. Las jóvenes la habían bañado y colocado en el lecho; le ofrecen un abanico y le dicen que le haga aire mientras ellas se van a bañar, invitándolo a él a bañarse después. Ellas se marchan. Es entonces cuando la muchacha se duerme. Él la mira (ego limis specto) y, después de comprobar que todo estaba como debía, cierra la puerta, quedándose con ella, dispuesto, como se puede suponer, a gozarla.

interea somnus uirginem opprimit. ego limis aspecto sic per flabellum clanculum; et simul alia circunspecto, satin' explorata sint. video esse. pessulum ostio obdo ${ }^{58}$.

(Ter. Eun. 601ss.)

53 Bence partía de Maldonado, como indica al final de su comentario con la abreviatura Mald.

54 En Fernández-Guerra $(1859,505)$ lleva el mismo número; en Astrana Marín $(1945,1577)$ el apunte es el XLIX.

55 M: act. III, scena IV, 601. En Fernández-Guerra y Astrana Marín: "Terentii Eunuchus".

56 "Yo miro de reojo". Mantenemos aspecto, que aparece tachado en el manuscrito, situándose encima specto. En la edición que manejó Quevedo se lee: aspecto; quien copió el apuntamiento u otra mano hizo la corrección partiendo de la edición que pudo tener ante sus ojos.

57 Puede verse en la página [23] del manuscrito. Trad.: "Falta 'oculis'. En efecto, limis es "transuersus" ('oblicuo'), de donde también se dice limen ('umbral', 'dintel'), porque es oblicuo para los que entran y los que salen. Y cuando las personas disimulan ver lo que ven, y miran no con el rostro de frente (recto), sino torcido (oblicuo), se dice que miran de reojo ('oblicuos'). Pero, aunque 'transversos' (limi) se dicen generalmente 'oblicuos' (obliqui), esto, sin embargo, se dice propiamente de los ojos".

58 "En esto el sueño se apodera de la muchacha; yo la miro de reojo, así con disimulo (el correspondiente ademán) detrás del abanico; a la vez con una mirada alrededor observo si todas las demás medidas están bien tomadas; veo que lo están; echo el cerrojo a la puerta". Trad. de Rubio $(1957,155)$. 
La traducción del profesor Lisardo Rubio, que hemos ofrecido en nota, expresa muy bien el sentido de la frase terenciana; el comentario que ofrece Quevedo aporta las razones, a la vez que explicaciones, de gramática. El comentario lo debió de tomar de su ejemplar de la edición de 1560. Ciertamente en este, en la página 293, en nota marginal al texto que copió Quevedo (ego limis aspecto), se lee: L. ${ }^{59}$ Limis. I. oblique. Nomen pro aduerbio, y en el comentario a pie de página de Antesignanus se lee lo mismo que Quevedo ha copiado (Deest oculis...oculis dicitur), aunque don Francisco ha omitido lo que precedía, a saber, el lema y el comienzo de la explicación (Ego limis asp.) Limis, si nominatiuus singularis est, transuersus significat: si septimus pluralis $)^{60}$.

Este comentario es el de Donato. Es seguro que lo copió de aquí, aunque suprimió el principio. Debió de ver claro que limis no era nominativo, sino que era ablativo de plural del adjetivo limus-a-um, y que en Terencio faltaba o se sobreentendía el sustantivo (oculis) al que "acompañaría" limis. No omitió, sin embargo, la relación entre limis y limen, o que tanto el adjetivo como el sustantivo se decía de los ojos.

Es defendible que tomara el texto de su ejemplar de la edición de 1560, porque en esta se lee aspecto, y aspecto se tacha en el manuscrito del Rebusco para escribir "sobre línea" specto, que se lee en muchas ediciones ${ }^{61}$. Podría haber copiado el texto de la edición de 1602, de la que pudo tener un ejemplar, porque en la biblioteca del Monasterio de san Martín de Madrid había uno, y es bien sabido que allí llegaron una buena parte de los libros de Quevedo; pero no lo hizo, porque aquí se lee specto, y no aspecto, y observamos, además, la omisión de uero en Cum uero Limi. Por otra parte, la edición de 1602 incluye una explicación que no aparece en el texto de Quevedo, posiblemente porque la edición de 1560 la sitúa después de dicuntur aspicere ${ }^{62}$.

Finalmente, a nuestro juicio, es muy posible que Quevedo copiase esta frase y el comentario de Donato, porque vio que limis oculis aspectare se decía en español ("mirar de reojo"), es decir, era una frase que, como algunas de Plauto (que también copió y leemos en el Rebusco de apuntamientos autógrafos), tenía su correspondencia en nuestra lengua. Se trataba, sin duda, de una más de las frases latinas que "literalmente, se usaban en el mismo sentido en castellano" ${ }^{63}$. Asimismo, como las frases plautinas, podría estar destinada también al tratado De la común razón de las letras y lenguas que proyectaba publicar Quevedo, como él mismo informa en el capítulo cuarto de su España defendida (Moya; Miralles, 2018, 118).

59 Con L se indica que lo dicho es de Bartholomaeus Latomus.

60 Ego limis asp<ecto>). Limis, si es nominativo singular, significa oblicuo (transuersus): si es ablativo de plural, falta oculis (deest oculis). Quevedo comienza con Deest oculis, que sintácticamente, pertenece a la frase anterior. En cuanto a septimus casus, lo hemos traducido por "ablativo". Cf. Iso (1975, 43-49).

61 En el manuscrito se lee autem en vez de igitur. Pudo ser un despiste de Quevedo.

${ }^{62}$ Cf. Terentius $(1602,154)$ : EGO LIMIS SPECTO. Limis, si nominatiuus singularis est, transuersus significat: si septimus pluralis, deest oculis. Nam limis est transuersus: unde limen dicitur quoque, quod ingredientibus exeuntibusque transuersum est. Quum igitur dissimulant homines se uidere quod uident, et non recta facie, sed

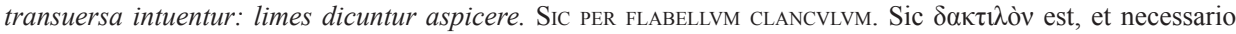
additum. Nam et limis et per flabellum sine demonstratione parum intelligitur. LIMIS SPECTO. Cum Limi dicantur obliqui generaliter: hoc tamen propie de oculis dicitur. En la edición de 1560, p. 293, se omite en este lugar desde Sic PER Flabellvm hasta Limis SPeCto. También se omite en Quevedo.

63 Así decía Quevedo en el epígrafe de las frases latinas de Plauto, que hemos editado y comentado. Cf. Moya; Gallego (2020). 


\section{A modo de conclusión}

Podríamos concluir volviendo al punto de partida. Quevedo conocía bien a Terencio; hemos podido mostrar que lo leyó, que el ejemplar de la edición de 1560 que lleva su firma lo manejó; lo deja claro uno de sus apuntamientos, en el que copia lo que lee en el margen de un verso que ha citado. Quevedo lee texto y comentario, como decía Tarsia (1997, 35): "leía los autores no de paso, sino margenándolos, con apuntar lo más notable, y con añadir, donde le parecía, su censura". En este caso valora lo que dice Terencio y no acepta lo que añadió el comentarista.

Quevedo debió de leer a Terencio completo. De sus seis comedias, cita cinco (todas menos Hecyra), aunque hay que reconocer que apenas unos versos en total.

Quevedo tradujo a Terencio, aunque solo dos versos de Phormio.

Como ocurre con otros autores, Quevedo llega a Terencio de modo indirecto y cita lo que encuentra en otros libros que también lee.

Los textos terencianos que hemos descubierto en Quevedo nos permiten deducir, de nuevo, que este autor debe de estar muy presente en la obra quevediana, y sería bueno intentar descubrir sus huellas.

En sus citas se puede constatar que Quevedo utiliza a Terencio no solo como alarde erudito, sino para dar mayor solidez a los textos sagrados. Y el término peregrina, que utiliza el poeta latino en Andria, le sirve para dejarle claro a Pineda que él podía, con toda razón, llamar "rameras" a las muchas mujeres a las que amó el rey Salomón; que alienigena es, como peregrina, lo mismo que meretrix.

Quevedo utiliza a Terencio para criticar las injusticias de la Justicia, el peligro que conlleva defender la summa iustitia con el texto de Heautontimorumenos, o la parcialidad de los jueces con un texto de Phormio.

También Terencio viene en su ayuda en un tema religioso. A Quevedo le agrada comprobar que el comediógrafo latino creía en las súplicas a los dioses, y que estos escuchaban a todos, aunque a los "buenos", sin duda, los atendían mejor.

Igualmente, parece claro que textos de Terencio tenían que estar presentes necesariamente en su obra De la común razón de las letras y lenguas; uno de ellos sería, sin duda, ego limis aspecto, que hemos comentado.

Por otra parte, haber localizado, con cierta garantía, obras de donde parten sus citas o annotationes, nos ha permitido descubrir nuevos libros que estuvieron en la biblioteca de Quevedo, como son: Commentarii in quatuor euangelistas de Maldonado o Symbolorum Imperatorium Classis secunda de Reusner.

Estos textos terencianos y la utilización de ellos por Quevedo hablan de sus lecturas, de sus conocimientos, de sus preocupaciones y de su talento.

\section{Bibliografía}

Alonso Veloso, M. ${ }^{\text {a J }}$ (2019), «La respuesta de Quevedo al Padre Pineda: una obra posiblemente censurada», Neophilologus 104, 49-67. DOI: https://doi.org/10.1007/s11061-01909610-z.

Astrana Marín, L. (1945), Francisco de Quevedo. Obras completas en Prosa, Madrid, Aguilar. Augustinus Hipponensis (1561), D. Aurelii Augustini Hipponensis Episcopi Quaestiones in uetus nouumque Testamentum, una cum reliquis illius voluminibus, 2 vols. (I: tomi quarti 
pars prima, cum indice sententiarumque indice locupletissimo, y II: tomi quarti pars secunda), Lugduni, apud haeredes Iacobi Iuntae.

Bence, Io. (1626), cf. Manuale in Sanctum (...).

Buendía, F. (19584), Don Francisco de Quevedo y Villegas, Obras completas, Tomo I: Obras en prosa, Madrid, Aguilar.

Díaz Martínez, E. M. ; Cacho Casal, R. (2012), Política de Dios, Gobierno de Cristo, en Francisco de Quevedo. Obras completas en Prosa, Volumen quinto (Dirección A. Rey, Coordinación $\mathrm{M}^{\mathrm{a}} \mathrm{J}$. Alonso Veloso), Madrid, Castalia, pp. 187-326.

Fernández-Guerra y Orbe, A. (1859), Obras de Don Francisco de Quevedo Villegas, Colección Completa, Tomo segundo, Madrid, B.A.E.

Iso Echegoyen, J. J. (1975), «El término ablatiuus en el Ars grammatica latina», CFC 9, 33-52.

Maldonado, J. de (1602), Ioannis Maldonati Andalusii (...) Commentarii in quatuor euangelistas (...), ex duobus in unum tomum redacti, Lugduni, Sumptibus Horatii Cardon.

Maldonado, J. de (1615), Ioannis Maldonati Sapharensis (...) Commentarii in quatuor euangelistas (...), Editio postrema, Lugduni, Sumptibus Horatii Cardon.

Manuale in Sanctum Iesu Christi Domini Nostri Euangelium, Ioannis Bence, Lugduni, Sumptibus Claudii Landry, 1626.

Moya del Baño, F. (2014), Quevedo y sus ediciones de textos clásicos. Las citas grecolatinas y la biblioteca clásica de Quevedo, Murcia, Editum.

Moya del Baño, F.; Gallego Moya, E. (2020), «Plauto en el Rebusco de apuntamientos autógrafos de Quevedo», Fortunatae 32 (2), e.p.

Moya del Baño, F.; Miralles Maldonado, J. C. (2018), Francisco de Quevedo. España defendida, A Coruña, Sielae.

Nebrija, A. (1529), Libri Minores de nouo correcti per Antonium Nebrissensem. Cum priuilegio Regali ne quis excudat aut uendat per decem annos. Compluti, in aedibus Michaelis de Eguia.

Nebrija, A. (2009), Ael. Antonii Nebrissenssis Gramm. Opera, Libri minores. Introducción, edición crítica y traducción de M. A. Gutiérrez, Salamanca, Universidad.

Pettegree, A.; Walsby, M. (2012), French Books III \& IV. Books published in France before 1601 in Latin and Languages other than French, Leiden-Boston, Brill.

Reusner N. (1602), Nicolai Reusneri Leorini Silesii Symbolorum Imperatorium Classis secunda, qua continentur Symbola Impp. Caesarumque Romanorum Graecorum: a Fl. Constantino Magno, usque ad Carolum Magnum, primum Caesarem Germanicum (...), Francofurti, Sumptibus ac Typis Ioannis Spieslii et hæredum Romani Beati.

Rubio, L. (1957), P. Terencio Afro. Comedias La Andriana - El eunuco, Texto revisado y traducido por Lisardo Rubio, v. I, Barcelona, Alma Mater.

Rubio, L. (1961), P. Terencio Afro. Comedias, Heautontimorumenos - Formión, Texto revisado y traducido por Lisardo Rubio, v. II, Barcelona, Alma Mater.

Rubio, L. (1966), P. Terencio Afro. Comedias, Hécira - Adelfos, Texto revisado y traducido por Lisardo Rubio, v. III, Barcelona, Alma Mater.

Ruiz de la Cuesta. A. (1984), El legado doctrinal de Quevedo: su dimensión política y filosófico-jurídica, Madrid, Tecnos.

Symbolorum Imperatorium Classis secunda, cf. Reusner.

Tarsia, P. de (1997=1663), Vida de don Francisco de Quevedo y Villegas. Reproducción facsimilar por M. Prieto Santiago. Prólogo de F.B. Pedraza Jiménez, Cuenca, Universidad de Castilla la Mancha. 
Terentius (1560), Terentius in quem triplex edita est P. Antesignani Rapistagnensis Commentatio (...), Editio secundi exempl., Lugduni, apud Mathiam Bonhome, sub Claua aurea ${ }^{64}$. Terentius (1602), Publii Terentii Carthaginiensis Afri Comoediae VI. Et in eas Aelii Donati (...) et Eugraphii (...) Commentaria. Fr. Lindenbrucnius, collatis MSS. ueteribusque exemplaribus recensuit, auxit, et Obseruationibus inlustrauit, adiecto Indice uberrimo, Parisiis, ex officina Plantiniana, apud Hadrianum Perier. 